\title{
A REDUCED KINETIC MECHANISM FOR PROPANE FLAMES
}

\author{
G. S. L. Andreis ${ }^{a}$, \\ R. S. Gomes ${ }^{\text {, }}$ \\ and A. L. De Bortoli ${ }^{b}$ \\ ${ }^{a}$ Federal University of Rio Grande do Sul \\ Graduate Program in Chemical Engineering \\ Street Engenheiro Luiz Englert $\mathrm{s} / \mathrm{n}^{\circ}$, \\ CEP. 90040-040, Porto Alegre, Brazil \\ greice.lorenzzetti@ufrgs.br \\ ${ }^{b}$ Federal University of Rio Grande do Sul \\ Graduate Program in Applied Mathematics \\ Av. Bento Gonçalves, 9500 \\ CEP. 91509-900, Porto Alegre, Brazi
}

\begin{abstract}
Propane is one of the simplest hydrocarbons that can be a representative of higher hydrocarbons used in many applications. Therefore, this work develops a ten-step reduced kinetic mechanism among 14 reactive species for the propane combustion. The model is based on the solution of the flamelet equations. The equations are discretized using the second-order space finite difference method, using LES (Large-Eddy Simulation). Obtained results compare favorably with data in the literature for a propane jet diffusion flame. The main advantage of this strategy is the decrease of the work needed to solve the system of governing equations.
\end{abstract}

Keywords: reduced mechanism, diffusion flames, propane

\section{NOMENCLATURE}

$A \quad$ frequency factor

$c_{p} \quad$ specific heat capacity at constant pressure, $J /(\operatorname{kg~K})$

Ea activation energy, $\mathrm{cal} / \mathrm{mol}$

$k$ reaction rate coefficient, (time) $)^{-1}$ (concentration) $)^{1-n}$, where $n$ is the order of the reaction $L_{e} \quad$ Lewis number

$Q_{k} \quad$ heat of combustion of the reaction $k, J / m o l$

$R \quad$ gas constant, $\mathrm{cal} /(\mathrm{mol} \mathrm{K})$

$R_{e} \quad$ Reynolds number

$S_{c} \quad$ Schmidt number

$t \quad$ dimensionless time

$T$ temperature, $K$

$\tilde{u}_{j}$ dimensionless velocity vector

$w_{k} \quad$ reaction rate of the reaction $k, \mathrm{~mol} /\left(\mathrm{cm}^{3} \mathrm{~s}\right)$

$W_{i} \quad$ molecular weight of species $i, \mathrm{~g} / \mathrm{mol}$

$x_{j} \quad$ dimensionless spatial coordinate

$\widetilde{Y}_{i} \quad$ mass fraction of the species $i$

$Y_{C 3 H 8,1}$ mass fraction of fuel in the fuel stream

$Y_{O 2,2}$ mass fraction of oxygen in the oxidizer stream

$\widetilde{Z} \quad$ global mixture fraction

$\tilde{Z}_{i} \quad$ mixture fraction of each fuel and products important species

$Z_{s t} \quad$ stoichiometric mixture fraction

\section{Greek symbols}

$\begin{array}{ll}\tilde{\chi} & \text { dimensionless scalar dissipation rate } \\ \beta & \text { temperature exponent } \\ \bar{\mu}_{T} & \text { dimensionless turbulent viscosity } \\ v & \text { stoichiometric mass ratio }\end{array}$

$v_{i, k} \quad$ stoichiometric coefficients of the species $i$ in the reaction $k$

$\rho$ density, $\mathrm{g} / \mathrm{cm}^{3}$
$\tau \quad$ dimensionless time defined in the coordinate
system attached to the stoichiometric surface

\section{INTRODUCTION}

Propane is an important fuel and its high temperature combustion is characterized by the rapid decomposition into smaller $\mathrm{C}_{1}-\mathrm{C}_{3}$ intermediates (Leung et al., 1993). In combustion and autoignition processes, the propane breaks down first into propene and then into products (Petrova and Williams, 2006). Propane is rapidly consumed on the rich side of the flames to produce a large amount of $\mathrm{C}_{1}$ and $\mathrm{C}_{2}$ intermediates, especially at low strain rate conditions. The attack by $\mathrm{H}$ and $\mathrm{OH}$ radicals are the major consumption paths for propane and the intermediate species, with the exception of the acetylene where the $\mathrm{O}$ atom attack is dominant (Leung et al., 1993).

Chemical kinetic modeling has become an important tool for interpreting and understanding the combustion phenomena (Leung and Lindstedt, 1995). A large amount of effort has been devoted to the development of detailed and reduced kinetic mechanisms for hydrocarbon combustion. Detailed kinetic mechanisms describing hydrocarbon combustion are conceptually structured in a hierarchical manner, with $\mathrm{H}_{2}$ and $\mathrm{CO}$ chemistry at the base, supplemented as needed by elementary reactions of larger chemical species (Qin et al., 2000). For the propane, detailed and reduced mechanisms were developed in the works from Leung et al. (1993), Leung and Lindstedt (1995), Qin et al. (2000), Marazioti and Koutmos (2002), Curran 
et al. (2004), Anetor et al. (2012), among others. According to Kennel et al. (1993), reduced mechanisms for propane premixed flames contains nine, six or four steps, and according to Leung et al. (1993), nine or seven steps for propane-air diffusion flames are needed.

In this work, good agreement has been obtained between data from the literature and predictions for the mass fraction of the major species.

\section{OBTAINMENT OF THE REDUCED KINETIC MECHANISM}

When detailed kinetic mechanisms are employed to analyze flames, a conservation equation must be solved for each species. Therefore, it is desirable to use simplified kinetic mechanisms that describe the reaction system in terms of few species. In this work is used a set of reactions for the propane combustion given by the references (Leung et al., 1993), (Mehl et al., 2009) and (http://web.eng.ucsd.edu/mae/groups/combustion/me chanism.html, consulted in 21 June 2012).

The reduction of the chemical kinetic mechanism is based on following steps (Peters, 1988):

- Estimate the order of magnitude of the reaction rate coefficients and define the main chain;

- Apply partial equilibrium and steady-state assumptions;

- Identify global reactions and their principal rates;

- Justify the assumptions by asymptotic analysis.

The reaction rate coefficients, (time) $)^{-1}$ (concentration) $^{1-n}$, where $n$ is the order of the reaction, are calculated using the modified Arrhenius equation, for $T=900 K$,

$$
k=A T^{\beta} \exp \left(-\frac{E a}{R T}\right)
$$

where $A$ is the frequency factor, $T$ the temperature, $K$, $\beta$ the temperature exponent, $E a$ the activation energy, $\mathrm{cal} / \mathrm{mol}$, and $R$ the gas constant, $\mathrm{cal} /(\mathrm{mol} \mathrm{K})$. The main chain is selected based on the coefficients $k$ of each elementary reaction, and is presented in the Fig. 1.

The reduction strategy is based on the introduction of steady-state and partial equilibrium assumptions. For a homogeneous system, the steadystate hypothesis is valid for those intermediate species that are produced by slow reactions and consumed by fast reactions, such that their concentration remains small (Turns, 2000). The assumption of partial equilibrium may be justified when the rate coefficients of both the forward and backward steps of a single reaction are much larger than all other rate coefficients (Peters, 1988).

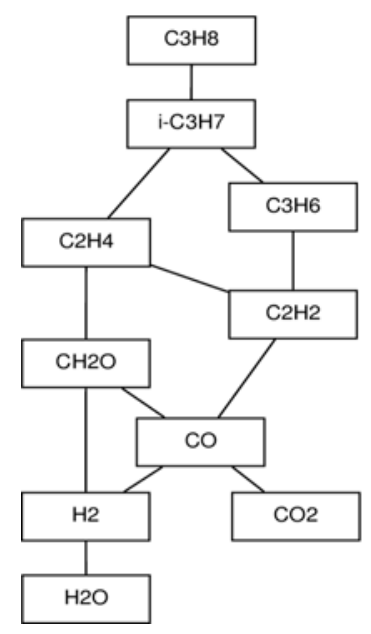

Figure 1. Diagram of the main chain for the propane reduced mechanism.

After applying the hypothesis of partial equilibrium for those reactions with high specific forward and backward rates, it remains the reactions of the Table 1. Considering the steady-state assumption for the species $\mathrm{C}_{2} \mathrm{H}_{3}, \mathrm{C}_{2} \mathrm{H}, \mathrm{CHCO}, \mathrm{CH}_{3}$, $\mathrm{HCO}, \mathrm{HO}_{2}$ and $\mathrm{O}$, it results the following ten-step mechanism among 14 species for the propane

$$
\begin{array}{lc}
I & 2 \mathrm{C}_{3} \mathrm{H}_{8}+\mathrm{O}_{2}+\mathrm{H}=\mathrm{i}-\mathrm{C}_{3} \mathrm{H}_{7}+\mathrm{C}_{2} \mathrm{H}_{4}+ \\
& \mathrm{CH}_{2}+2 \mathrm{H}_{2} \mathrm{O} \\
\text { II } & \mathrm{i}-\mathrm{C}_{3} \mathrm{H}_{7}+\mathrm{OH}=\mathrm{C}_{3} \mathrm{H}_{6}+\mathrm{H}_{2} \mathrm{O} \\
\text { III } & \mathrm{C}_{3} \mathrm{H}_{6}=\mathrm{C}_{2} \mathrm{H}_{2}+\mathrm{CH}_{2}+\mathrm{H}_{2} \\
\text { IV } & \mathrm{C}_{2} \mathrm{H}_{4}+0.6 \mathrm{O}_{2}=0.6 \mathrm{C}_{2} \mathrm{H}_{2}+0.4 \mathrm{CH}_{2} \mathrm{O}+ \\
& 0.4 \mathrm{CO}+0.6 \mathrm{H}_{2}+0.4 \mathrm{H}_{2} \mathrm{O} \\
\text { V } & 2 \mathrm{CH}_{2}+2 \mathrm{O}_{2}=\mathrm{CO}+\mathrm{CO}_{2}+\mathrm{OH}+3 \mathrm{H} \\
\text { VI } & \mathrm{C}_{2} \mathrm{H}_{2}+1.5 \mathrm{O}_{2}=2 \mathrm{CO}+\mathrm{H}_{2} \mathrm{O} \\
\text { VII } \mathrm{CH}_{2} \mathrm{O}=\mathrm{CO}+\mathrm{H}_{2} \\
\text { VIII } \mathrm{CO}+\mathrm{H}_{2} \mathrm{O}=\mathrm{CO}_{2}+\mathrm{H}_{2} \\
\text { IX } & 3 \mathrm{H}_{2}+\mathrm{O}_{2}=2 \mathrm{H}_{2} \mathrm{O}+2 \mathrm{H}^{2} \\
\text { X } & \mathrm{H}+\mathrm{H}+\mathrm{M}=\mathrm{H}_{2}+\mathrm{M}
\end{array}
$$

where $\mathrm{M}$ is an inert needed to remove the bond energy that is liberated during recombination.

Table1. Propane mechanism rate coefficients ${ }^{1}$.

\begin{tabular}{lccr}
\hline \multicolumn{1}{c}{ Reactions } & $\boldsymbol{A}$ & $\beta$ & \multicolumn{1}{c}{ Ea } \\
\hline 1. $\mathrm{O}_{2}+\mathrm{H}=\mathrm{OH}+\mathrm{O}^{*}$ & $2.00 \mathrm{E}+14$ & 0.00 & 70.3 \\
\hline 2. $\mathrm{H}_{2}+\mathrm{O}=\mathrm{OH}+\mathrm{H}^{*}$ & $5.06 \mathrm{E}+04$ & 2.67 & 26.3 \\
\hline $3 . \mathrm{H}_{2}+\mathrm{OH}=\mathrm{H}_{2} \mathrm{O}+\mathrm{H}^{*}$ & $1.00 \mathrm{E}+08$ & 1.60 & 13.8 \\
\hline $4 . \mathrm{H}+\mathrm{H}_{2} \mathrm{O}=\mathrm{H}_{2}+\mathrm{OH}^{* * *}$ & $2.29 \mathrm{E}+09$ & 1.40 & 18320 \\
\hline $5 . \mathrm{H}_{2}+\mathrm{M}=\mathrm{H}+\mathrm{H}+\mathrm{M}^{* * *}$ & $4.58 \mathrm{E}+19$ & -1.40 & 104400
\end{tabular}

\footnotetext{
${ }^{1}$ Units are $\mathrm{mol}, \mathrm{cm}^{3}, \mathrm{~s}, \mathrm{~K}$ and $\mathrm{kJ} / \mathrm{mol}$ for *Leung et al. (1993), **http://web.eng.ucsd.edu/mae/groups/combustion/mechanism.ht $\mathrm{ml}$, consulted in $21 \mathrm{June} 2012$, and $\mathrm{mol}, \mathrm{cm}^{3}, \mathrm{~s}, K$ and $\mathrm{cal} / \mathrm{mol}$ for ***Mehl et al. (2009).
} 


\begin{tabular}{|c|c|c|c|}
\hline 6. $\mathrm{O}_{2}+\mathrm{M}=\mathrm{O}+\mathrm{O}+\mathrm{M}^{* * * *}$ & $4.42 \mathrm{E}+17$ & -0.63 & 118900 \\
\hline 7. $\mathrm{O}+\mathrm{O}+\mathrm{M}=\mathrm{O}_{2}+\mathrm{M}^{* * *}$ & $6.17 \mathrm{E}+15$ & -0.50 & 0 \\
\hline 8. $\mathrm{O}+\mathrm{H}+\mathrm{M}=\mathrm{OH}+\mathrm{M}^{* * *}$ & $4.71 \mathrm{E}+18$ & -1.00 & 0 \\
\hline 9. $\mathrm{HO}_{2}+\mathrm{H}=\mathrm{H}_{2} \mathrm{O}+\mathrm{O}^{*}$ & $3.00 \mathrm{E}+13$ & 0.00 & 7.2 \\
\hline 10. $\mathrm{HO}_{2}+\mathrm{M}=\mathrm{H}+\mathrm{O}_{2}+\mathrm{M}^{* * *}$ & $3.09 \mathrm{E}+12$ & 0.52 & 48870 \\
\hline 11. $\mathrm{HO}_{2}+\mathrm{H}=\mathrm{H}_{2}+\mathrm{O}_{2} * * *$ & $1.66 \mathrm{E}+13$ & 0.00 & 823 \\
\hline 12. $\mathrm{HO}_{2}+\mathrm{OH}=\mathrm{H}_{2} \mathrm{O}+\mathrm{O}_{2}{ }^{* * *}$ & $1.97 \mathrm{E}+10$ & 0.96 & -328.4 \\
\hline 13. $\mathrm{H}+\mathrm{H}+\mathrm{M}=\mathrm{H}_{2}+\mathrm{M}^{*}$ & $1.80 \mathrm{E}+18$ & -1.00 & 0 \\
\hline 14. $\mathrm{CO}+\mathrm{OH}=\mathrm{CO}_{2}+\mathrm{H}^{*}$ & $4.40 \mathrm{E}+06$ & 1.50 & -3.1 \\
\hline 15. $\mathrm{HCO}+\mathrm{O}_{2}=\mathrm{CO}+\mathrm{HO}_{2} * * *$ & $7.58 \mathrm{E}+12$ & 0.00 & 410 \\
\hline 16. $\mathrm{CH}_{2} \mathrm{O}+\mathrm{H}=\mathrm{HCO}+\mathrm{H}_{2} * * *$ & $5.74 \mathrm{E}+07$ & 1.90 & 2740 \\
\hline 17. $\mathrm{CH}_{2}+\mathrm{O}_{2}=\mathrm{CO}+\mathrm{OH}+\mathrm{H}^{*}$ & $6.50 \mathrm{E}+12$ & 0.00 & 6.3 \\
\hline 18. $\mathrm{CH}_{2}+\mathrm{O}_{2}=\mathrm{CO}_{2}+\mathrm{H}+\mathrm{H}^{*}$ & $6.50 \mathrm{E}+12$ & 0.00 & 6.3 \\
\hline 19. $\mathrm{CH}_{3}+\mathrm{H}=\mathrm{CH}_{2}+\mathrm{H}_{2}$ * & $1.80 \mathrm{E}+14$ & 0.00 & 63 \\
\hline 20. $\mathrm{CH}_{3}+\mathrm{O}_{2}=\mathrm{CH}_{2} \mathrm{O}+\mathrm{OH}^{*}$ & $3.40 \mathrm{E}+11$ & 0.00 & 37.4 \\
\hline 21. $\mathrm{CHCO}+\mathrm{O}=\mathrm{CO}+\mathrm{CO}+\mathrm{H}^{*}$ & $1.00 \mathrm{E}+14$ & 0.00 & 0 \\
\hline 22. $\mathrm{C}_{2} \mathrm{H}+\mathrm{O}_{2}=\mathrm{CHCO}+\mathrm{O}^{*}$ & $5.00 \mathrm{E}+13$ & 0.00 & 3.6 \\
\hline 23. $\mathrm{C}_{2} \mathrm{H}_{2}+\mathrm{OH}=\mathrm{C}_{2} \mathrm{H}+\mathrm{H}_{2} \mathrm{O}^{*}$ & $1.00 \mathrm{E}+13$ & 0.00 & 29.3 \\
\hline 24. $\mathrm{C}_{2} \mathrm{H}_{3}=\mathrm{C}_{2} \mathrm{H}_{2}+\mathrm{H}^{*}$ & $2.00 \mathrm{E}+14$ & 0.00 & 166.29 \\
\hline 25. $\mathrm{C}_{2} \mathrm{H}_{4}+\mathrm{O}=\mathrm{CH}_{3}+\mathrm{CO}+\mathrm{H}^{*}$ & $1.60 \mathrm{E}+09$ & 1.20 & 3.1 \\
\hline 26. $\mathrm{C}_{2} \mathrm{H}_{4}+\mathrm{OH}=\mathrm{C}_{2} \mathrm{H}_{3}+\mathrm{H}_{2} \mathrm{O}^{*}$ & $3.00 \mathrm{E}+13$ & 0.00 & 12.6 \\
\hline 27. $\mathrm{C}_{2} \mathrm{H}_{4}+\mathrm{H}=\mathrm{C}_{2} \mathrm{H}_{3}+\mathrm{H}_{2}$ *** & $5.07 \mathrm{E}+07$ & 1.93 & 12950 \\
\hline 28. $\mathrm{C}_{2} \mathrm{H}_{4}+\mathrm{O}=\mathrm{CH}_{3}+\mathrm{HCO}^{* * *}$ & $8.56 \mathrm{E}+06$ & 1.88 & 183 \\
\hline 29. $\mathrm{C}_{3} \mathrm{H}_{6}=\mathrm{C}_{2} \mathrm{H}_{3}+\mathrm{CH}_{3} * * *$ & $2.73 \mathrm{E}+62$ & -13.3 & 123200 \\
\hline 30. $\mathrm{i}-\mathrm{C}_{3} \mathrm{H}_{7}=\mathrm{C}_{2} \mathrm{H}_{4}+\mathrm{CH}_{3} *$ & $6.30 \mathrm{E}+13$ & 0.00 & 154.5 \\
\hline 31. i- $\mathrm{C}_{3} \mathrm{H}_{7}+\mathrm{O}_{2}=\mathrm{C}_{3} \mathrm{H}_{6}+\mathrm{HO}_{2}{ }^{*}$ & $1.00 \mathrm{E}+12$ & 0.00 & 20.9 \\
\hline 32. $\mathrm{C}_{3} \mathrm{H}_{8}+\mathrm{O}_{2}=\mathrm{i}-\mathrm{C}_{3} \mathrm{H}_{7}+\mathrm{HO}_{2} * *$ & $4.00 \mathrm{E}+13$ & 0.00 & 199 \\
\hline 33. $\mathrm{C}_{3} \mathrm{H}_{8}+\mathrm{OH}=\mathrm{i}-\mathrm{C}_{3} \mathrm{H}_{7}+\mathrm{H}_{2} \mathrm{O}^{* * *}$ & $1.05 \mathrm{E}+10$ & 0.97 & 1586 \\
\hline
\end{tabular}

The obtained reduced mechanism can be justified by an asymptotic analysis. For the set of elementary reactions shown in the Table 1, the balance equations can be written as

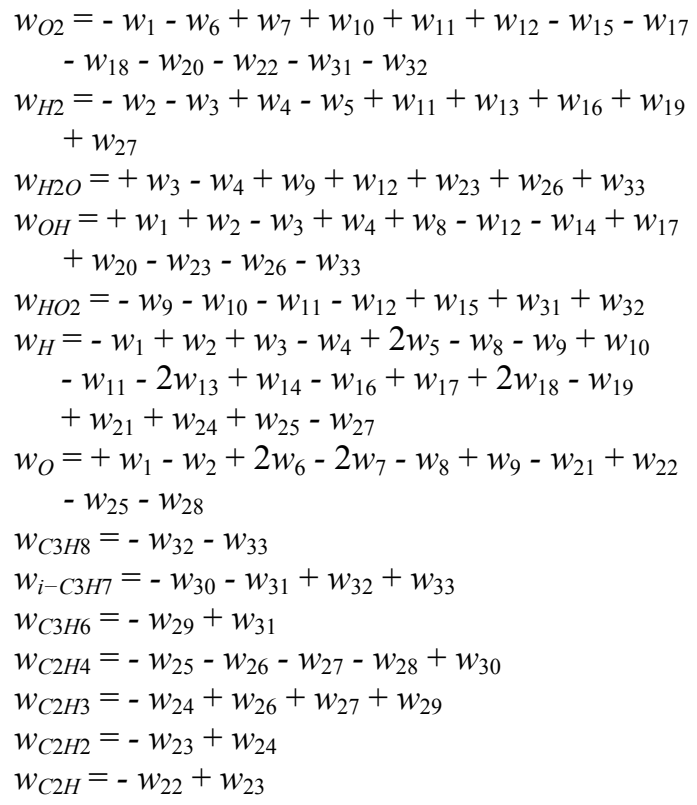

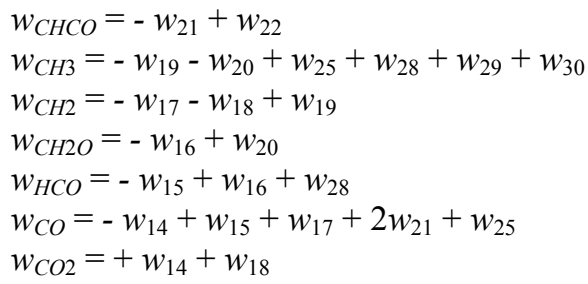

where $w_{k}$ represents the reaction rate of the reaction $k$, $\mathrm{mol} /\left(\mathrm{cm}^{3} \mathrm{~s}\right)$. The positive sign refers to the species which appears as products in the elementary reaction, while the negative sign refers to the species that appear as reactants. For example, in the reaction 1: $\mathrm{O}_{2}+\mathrm{H}=\mathrm{OH}+\mathrm{O}, w_{\mathrm{O} 2}=-w_{1}$ and $w_{\mathrm{OH}}=+w_{1}$, repeating this procedure for all other species and reactions of the mechanism.

The application of the steady-state hypothesis for the species $\mathrm{C}_{2} \mathrm{H}_{3}, \mathrm{C}_{2} \mathrm{H}, \mathrm{CHCO}, \mathrm{CH}_{3}, \mathrm{HCO}, \mathrm{HO}_{2}$ and $\mathrm{O}$, leads to 8 algebraic equations among the reaction rates $w_{k}$ :

$$
\begin{aligned}
& w_{8}=+w_{1}-w_{2}+2 w_{6}-2 w_{7}+w_{9}-w_{25}-w_{28} \\
& w_{12}=-w_{9}-w_{10}-w_{11}+w_{16}+w_{31}+w_{32}+w_{28} \\
& w_{15}=+w_{16}+w_{28} \\
& w_{18}=+4 w_{1}-2 w_{3}+2 w_{4}+4 w_{6}-4 w_{7}+4 w_{9} \\
& +2 w_{10}+2 w_{11}-2 w_{14}-2 w_{16}+w_{17}+w_{20} \\
& -2 w_{23}-w_{25}-2 w_{26}-3 w_{28}+2 w_{30}-3 w_{32}-3 w_{33} \\
& w_{19}=-w_{20}+w_{25}+w_{28}+w_{29}+w_{30} \\
& w_{21}=+w_{23} \\
& w_{22}=+w_{23} \\
& w_{24}=+w_{26}+w_{27}+w_{29}
\end{aligned}
$$

Thus, the balance equations can be rewritten as

$$
\begin{aligned}
& w_{O 2}=-5 w_{1}+2 w_{3}-2 w_{4}-5 w_{6}+5 w_{7}-5 w_{9}-2 w_{10} \\
& \quad-2 w_{11}+2 w_{14}+2 w_{16}-2 w_{17}-2 w_{20}+w_{23} \\
& \quad+w_{25}+2 w_{26}+3 w_{28}-2 w_{30}+3 w_{32}+3 w_{33} \\
& w_{H 2}=-w_{2}-w_{3}+w_{4}-w_{5}+w_{11}+w_{13}+w_{16}-w_{20} \\
& \quad+w_{25}+w_{27}+w_{28}+w_{29}+w_{30} \\
& w_{H 2 O}=+w_{3}-w_{4}-w_{10}-w_{11}+w_{16}+w_{23}+w_{26} \\
& \quad+w_{28}+w_{31}+w_{32}+w_{33} \\
& w_{O H}=+2 w_{1}-w_{3}+w_{4}+2 w_{6}-2 w_{7}+2 w_{9}+w_{10} \\
& \quad+w_{11}-w_{14}-w_{16}+w_{17}+w_{20}-w_{23}-w_{25}-w_{26} \\
& \quad-2 w_{28}-w_{31}-w_{32}-w_{33} \\
& w_{H}=+6 w_{1}+2 w_{2}-3 w_{3}+3 w_{4}+2 w_{5}+6 w_{6}-6 w_{7} \\
& \quad+6 w_{9}+5 w_{10}+3 w_{11}-2 w_{13}-3 w_{14}-5 w_{16} \\
& \quad+3 w_{17}+3 w_{20}-3 w_{23}-w_{25}-3 w_{26}-6 w_{28} \\
& \quad+3 w_{30}-6 w_{32}-6 w_{33} \\
& w_{C 3 H 8}=-w_{32}-w_{33} \\
& w_{i-C 3 H 7}=-w_{30}-w_{31}+w_{32}+w_{33} \\
& w_{C 3 H 6}=-w_{29}+w_{31} \\
& w_{C 2 H 4}=-w_{25}-w_{26}-w_{27}-w_{28}+w_{30} \\
& w_{C 2 H 2}=-w_{23}+w_{26}+w_{27}+w_{29} \\
& w_{C H 2}=-4 w_{1}+2 w_{3}-2 w_{4}-4 w_{6}+4 w_{7}-4 w_{9} \\
& \quad-2 w_{10}-2 w_{11}+2 w_{14}+2 w_{16}-2 w_{17} \\
& \quad-2 w_{20}+2 w_{23}+2 w_{25}+2 w_{26}+4 w_{28}+w_{29} \\
& -w_{30}+3 w_{32}+3 w_{33} \\
& w_{C H 2 O}=-w_{16}+w_{20} \\
& w_{C O}=-w_{14}+w_{16}+w_{17}+2 w_{23}+w_{25}+w_{28} \\
& w_{C O 2}=+4 w_{1}-2 w_{3}+2 w_{4}+4 w_{6}-4 w_{7}+4 w_{9}
\end{aligned}
$$


$+2 w_{10}+2 w_{11}-w_{14}-2 w_{16}+w_{17}+w_{20}-2 w_{23}$

$-w_{25}-2 w_{26}-3 w_{28}+2 w_{30}-3 w_{32}-3 w_{33}$

resulting in the mechanism $I-X$. From the reactions $I$ $X$, it is observed that the production rates of the 14 species, which appear explicitly in the reduced mechanism, can be expressed in terms of 10 global rates as:

$$
\begin{aligned}
& w_{O 2}=-w_{I}-0.6 w_{I V}-2 w_{V}-1.5 w_{V I}-w_{I X} \\
& w_{H 2}=w_{I I I}+0.6 w_{I V}+w_{V I I}+w_{V I I}-3 w_{I X}+w_{X} \\
& w_{H 2 O}=2 w_{I}+w_{I I}+0.4 w_{I V}+w_{V I}-w_{V I I}+2 w_{I X} \\
& w_{O H}=-w_{I I}+w_{V} \\
& w_{H}=-w_{I}+3 w_{V}+2 w_{I X}-2 w_{X} \\
& w_{C 3 H 8}=-2 w_{I} \\
& w_{i-C 3 H 7}=w_{I}-w_{I I} \\
& w_{C 3 H 6}=w_{I I}-w_{I I I} \\
& w_{C 2 H 4}=w_{I}-w_{I V} \\
& w_{C 2 H 2}=w_{I I I}+0.6 w_{I V}-w_{V I} \\
& w_{C H 2}=w_{I}+w_{I I I}-2 w_{V} \\
& w_{C H 2 O}=0.4 w_{I V}-w_{V I I} \\
& w_{C O}=0.4 w_{I V}+w_{V}+2 w_{V I}+w_{V I I}-w_{V I I I} \\
& w_{C O 2}=w_{V}+w_{V I I I}
\end{aligned}
$$

where

$$
\begin{aligned}
& w_{I}=0.5\left(w_{32}+w_{33}\right) \\
& w_{I I}=w_{30}+w_{31}-0.5\left(w_{32}+w_{33}\right) \\
& w_{I I I}=w_{29}+w_{30}-0.5\left(w_{32}+w_{33}\right) \\
& \begin{aligned}
w_{I V} & =w_{25}+w_{26}+w_{27}+w_{28}-w_{30} \\
& +0.5\left(w_{32}+w_{33}\right) \\
w_{V} & =2 w_{1}-w_{3}+w_{4}+2 w_{6}-2 w_{7}+2 w_{9}+w_{10} \\
& +w_{11}-w_{14}-w_{16}+w_{17}+w_{20}-w_{23}-w_{25}-w_{26} \\
& -2 w_{28}+w_{30}-1.5\left(w_{32}+w_{33}\right) \\
w_{V I} & =w_{23}+0.6 w_{25}-0.4 w_{26}-0.4 w_{27}+0.6 w_{28} \\
& +0.4 w_{30}-0.2\left(w_{32}+w_{33}\right) \\
w_{V I I} & =w_{16}-w_{20}+0.4\left(w_{25}+w_{26}+w_{27}+w_{28}\right. \\
& \left.-w_{30}\right)+0.2\left(w_{32}+w_{33}\right) \\
w_{V I I I} & =2 w_{1}-w_{3}+w_{4}+2 w_{6}-2 w_{7}+2 w_{9}+w_{10} \\
& +w_{11}-w_{16}-w_{23}-w_{26}-w_{28}+w_{30} \\
& -1.5\left(w_{32}+w_{33}\right) \\
w_{I X} & =w_{1}+w_{6}-w_{7}+w_{9}-0.5\left(w_{23}+w_{25}+w_{28}\right. \\
& \left.+w_{32}+w_{33}\right) \\
w_{X} & =w_{1}-w_{2}-w_{5}+w_{6}-w_{7}+w_{9}-w_{10}+w_{13} \\
& +w_{16}-0.5 w_{23}-1.5 w_{25}-0.5 w_{28}
\end{aligned}
\end{aligned}
$$

\section{NUMERICAL PROCEDURE}

To validate the reduced mechanism developed for the propane, consider the simulation of a jet diffusion flame. For the combustion process, the set of equations for the chemistry includes the temperature, mixture fraction and species mass fraction equations. Favre filtering, or density weighted Favre filtering, becomes convenient when writing the governing equations for turbulent flows. The variables are Favre averaged or density weighted by $\tilde{f}=\overline{\rho f} / \bar{\rho}$, where the bar denotes the standard LES (Large-Eddy Simulation) filtering (Qin et al., 2000), (Steiner and Bushe, 1998), and $\rho$ is the density, $\mathrm{g} / \mathrm{cm}^{3}$. In these results it is employed the Lagrangian flamelet model for the chemistry, which allows to decouple the fluid flow from the chemistry problem. As combustion occurs in a thin layer of the flame, where the local mixture fraction gradient is sufficiently high, we introduce an orthogonal coordinate system attached to the surface of the stoichiometric mixture. The equations in nondimensionalised form can be derived by applying a spatial, density-weighted filter, resulting in for the:

- Mixture fraction

$$
\frac{\partial(\bar{\rho} \tilde{Z})}{\partial t}+\frac{\partial\left(\bar{\rho} \tilde{u}_{j} \tilde{Z}\right)}{\partial x_{j}}=\frac{\partial}{\partial x_{j}}\left(\frac{\bar{\mu}_{T}}{R_{e} S_{c}} \frac{\partial \tilde{Z}}{\partial x_{j}}\right)
$$

- Temperature

$$
\frac{\partial \widetilde{T}}{\partial \tau}-\frac{a \tilde{\chi}}{2} \frac{\partial^{2} \widetilde{T}}{\partial \widetilde{Z}^{2}}=\tilde{\dot{w}}_{T}
$$

- $\quad$ Species mass fractions

$$
\frac{\partial \tilde{Y}_{i}}{\partial \tau}-\frac{a \tilde{\chi}}{2 L_{e}} \frac{\partial^{2} \tilde{Y}_{i}}{\partial \widetilde{Z}^{2}}= \pm \widetilde{\dot{w}}_{i}
$$

where ' $\sim$ ' denotes the Favre averaged variables; $\widetilde{Z}=\sum_{i=1}^{n} \widetilde{Z}_{i}$ is the global mixture fraction, $\widetilde{Z}_{i}$ the mixture fraction of each fuel and products important species $\left(\mathrm{C}_{3} \mathrm{H}_{8}, \mathrm{i}-\mathrm{C}_{3} \mathrm{H}_{7}, \mathrm{C}_{3} \mathrm{H}_{6}, \mathrm{C}_{2} \mathrm{H}_{4}, \mathrm{C}_{2} \mathrm{H}_{2}, \mathrm{CH}_{2} \mathrm{O}\right.$, $\mathrm{CH}_{2}, \mathrm{CO}, \mathrm{CO}_{2}, \mathrm{H}_{2}$ and $\left.\mathrm{H}_{2} \mathrm{O}\right), \widetilde{Y}_{i}$ the mass fraction of the species $i, t$ the time, $\tilde{u}_{j}$ the velocity vector, $x_{j}$ the spatial coordinate, $\bar{\mu}_{T}$ the turbulent viscosity, $\tau$ the time defined in the coordinate system attached to the stoichiometric surface, $\quad a=\Delta Z Z_{s t}\left(1-Z_{s t}\right)$, $\Delta Z \approx 2 Z_{s t}, \quad \tilde{\chi}$ is the scalar dissipation rate, $\tilde{\dot{w}}_{T}=\left(\sum_{k=1}^{r} Q_{k} \widetilde{w}_{k}\right) / c_{p}, \quad \tilde{\dot{w}}_{i}=W_{i} \sum_{k=1}^{r} v_{i, k} \widetilde{w}_{k} \quad$ the reaction rate of the species $i, Q_{k}$ the heat of combustion of the reaction $k, J / m o l, c_{p}$ the specific heat capacity at constant pressure, $J /(k g K), W_{i}$ the molecular weight of species $i, \mathrm{~g} / \mathrm{mol}, v_{i, k}$ the stoichiometric coefficients of the species $i$ in the reaction $k$, and $\widetilde{w}_{k}$ the reaction rate of the reaction $k$, $R_{e}$ the Reynolds, $S_{c}$ the Schmidt, and $L_{e}$ the Lewis numbers.

The stoichiometric mixture fraction is obtained considering the global mechanism for propane combustion,

$$
\mathrm{C}_{3} \mathrm{H}_{8}+5 \mathrm{O}_{2}=3 \mathrm{CO}_{2}+4 \mathrm{H}_{2} \mathrm{O}
$$

through the expression

$$
Z_{s t}=\left(1+\frac{v Y_{C 3 H 8,1}}{Y_{O 2,2}}\right)^{-1}
$$


where $v$ is the stoichiometric mass ratio, $Y_{C 3 H 8,1}$ the mass fraction of fuel in the fuel stream $\left(Y_{C 3 H 8,1}=1\right)$, and $Y_{O 2,2}$ the mass fraction of oxygen in the oxidizer $\operatorname{stream}\left(Y_{O 2,2}=0.21\right)$.

The differential equations are discretized based on the central second order finite difference scheme. To check the reduced mechanism two approaches were adopted. First, the mechanism was implemented in the solver DASSL (Differential/Algebraic Systems Solver) (Petzold, 1982). After, the flamelet equations were implemented.

\section{SOLVER DASSL}

This solver implements the Backward Differentiation Formulas of orders one through five to solve implicit differential equations for initial values of $y$ and $y_{0}$. These values must be consistent, that is, if $t_{0}, y_{0}$ and $y_{0}^{\prime}$ are the given initial values, they must satisfy $f\left(t_{0} ; y_{0} ; y_{0}{ }^{\prime}\right)=0$ (Brenan et al., 1996). The resulting nonlinear system at each time-step is solved by Newton's method.

The subroutine solves the system from $t_{0}$ to $t_{\text {out }}$ (final time of integration). It also allows to continue the solution to get results at additional $t_{\text {out }}$. This is the interval mode of operation. Intermediate results can also be obtained easily by using the intermediateoutput capability. The linear systems are solved using routines from the LINPACK subroutine package (Dongarra et al., 1979). Error handling is accomplished using routines from the SLATEC common mathematical library package. This code performs well for stiff ordinary differential equations (ODE) and for differential/algebraic equations (DAE) of moderate size, where it is appropriate to treat the Jacobian matrix with dense or banded direct LU decomposition. For large-scale stiff ODE and DAE problems, it should be consider to employ the DASPK. For ODE or DAE problems which must stop at the root of a given function of the solution, the user should consider DASKR. Moreover, the code includes an extensive amount of documentation (see Petzold (1982)).

Although DASSL is a code written for problems of index $\leq 1$, it can handle some of the higher index problems by adjusting the error control.

The results produced for the principal mass fractions of chemical species of the reduced mechanism are presented in the Table 2. Satisfactory results were obtained compared to the results given by Leung et al. (1993) (Table 2).

Table 2. Results from Solver DASSL.

\begin{tabular}{ccc}
\hline $\begin{array}{c}\text { Mass } \\
\text { fraction }\end{array}$ & Results from DASSL & $\begin{array}{c}\text { Data } \\
\text { (Leung } \text { et } \\
\text { al., 1993) }\end{array}$ \\
\hline $\mathrm{Y}_{\mathrm{C} 3 \mathrm{H} 8}$ & $0.000000000000000 \mathrm{E}+00$ & 0.0000 \\
\hline $\mathrm{Y}_{\mathrm{O} 2}$ & $0.000000000000000 \mathrm{E}+00$ & 0.0000 \\
\hline $\mathrm{Y}_{\mathrm{H} 2 \mathrm{O}}$ & $0.154535365116772 \mathrm{E}+00$ & 0.1420 \\
\hline
\end{tabular}

\begin{tabular}{lll}
\hline $\mathrm{Y}_{\mathrm{CO} 2}$ & $0.793807529862030 \mathrm{E}-01$ & 0.0802 \\
\hline $\mathrm{Y}_{\mathrm{CO}}$ & $0.598568131360495 \mathrm{E}-01$ & 0.0607 \\
\hline $\mathrm{Y}_{\mathrm{H} 2}$ & $0.331286126648532 \mathrm{E}-01$ & 0.0340 \\
\hline
\end{tabular}

Figure 2 presents the mass fractions for the $\mathrm{C}_{3} \mathrm{H}_{8}, \mathrm{O}_{2}$ and $\mathrm{H}_{2} \mathrm{O}$ along the time. The results from solver DASSL shows the decreasing of the fuel and oxidant, and the increasing of the product $\mathrm{H}_{2} \mathrm{O}$ during the burn.

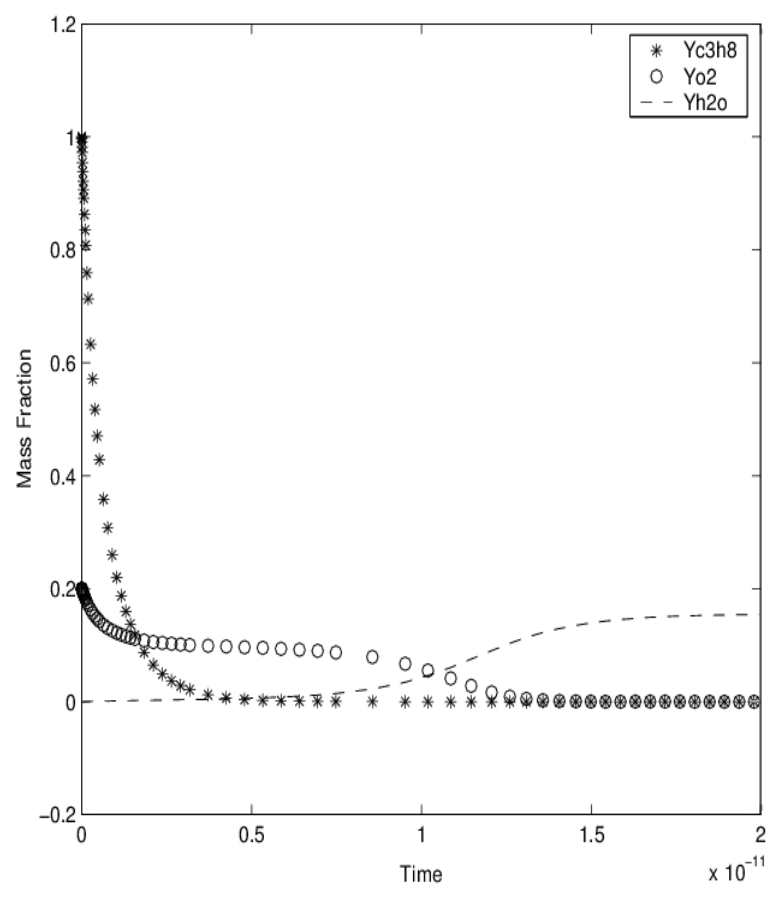

Figure 2. Numerical results for the mass fraction of fuel, oxidant and water vapor, along the time obtained via DASSL (for the reduced kinetic mechanism).

\section{NUMERICAL RESULTS}

Now, it is presented the numerical results for the Eqs. (2)-(4). The numerical results are compared with the skeletal chemical mechanism of 87-step for the propane (Leung et al., 1993). In the figures, numerical results are indicated with "num".

Figure 3 shows the comparison for the propane mass fraction along the mixture fraction space. The mixture fraction measures the reactants mixing and is mainly related to the large scale motions of the flow. The solution indicates the decreasing behavior of the propane mass fraction.

The behavior of the oxidizer $\mathrm{O}_{2}$ is given in the Fig. 4. For the reduced mechanism proposed, the mass fraction of $\mathrm{O}_{2}$ decreases more slowly.

Figure 5 shows the mass fractions for the major species, $\mathrm{H}_{2} \mathrm{O}$ and $\mathrm{CO}_{2}$. The $\mathrm{H}_{2} \mathrm{O}$ species was well predicted. The carbon dioxide mass fraction was reasonably well predicted. 


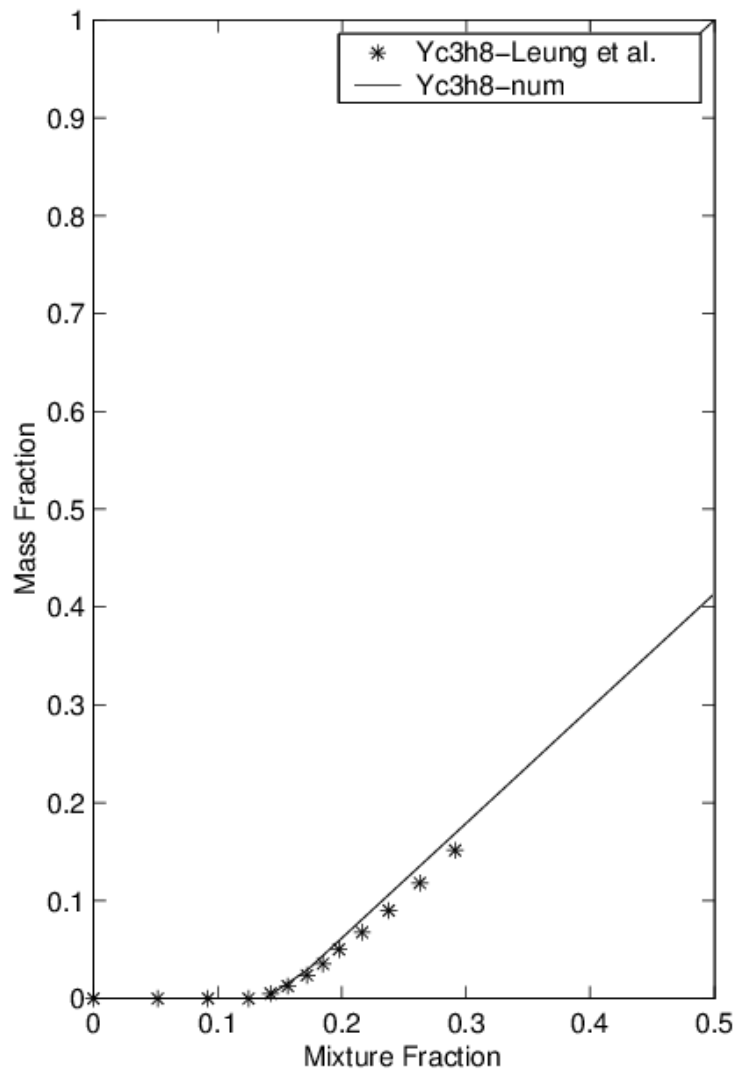

Figure 3. Numerical results for the mass fraction of fuel along the mixture fraction space.

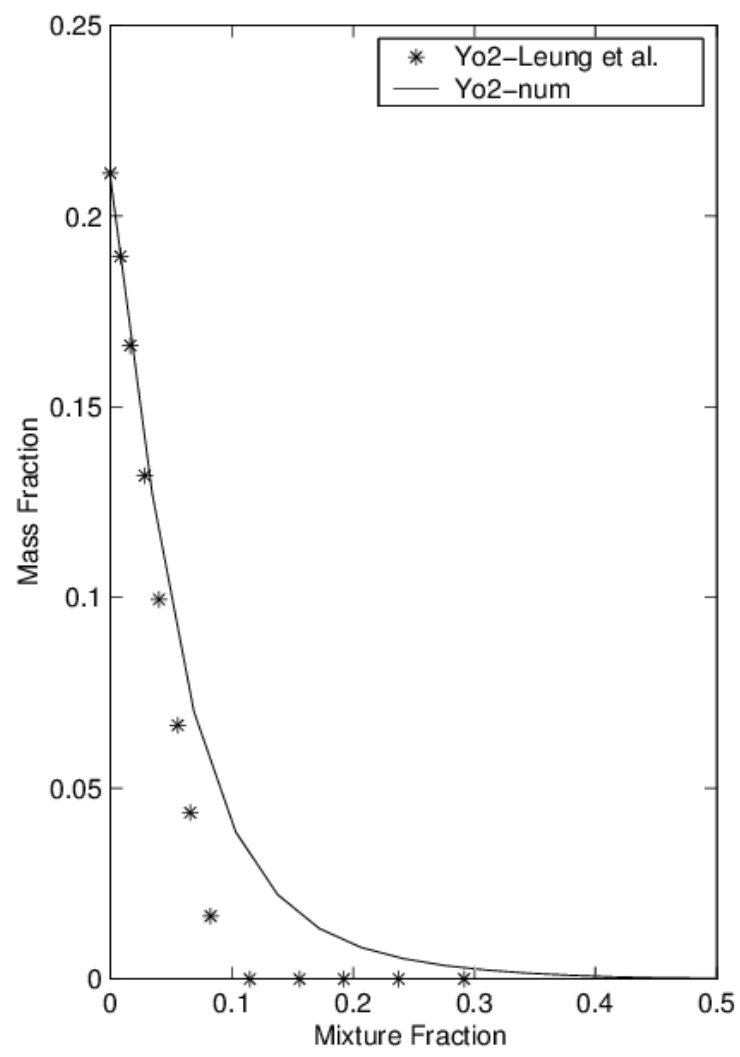

Figure 4. Numerical results for the mass fraction of $\mathrm{O}_{2}$ along the mixture fraction space.

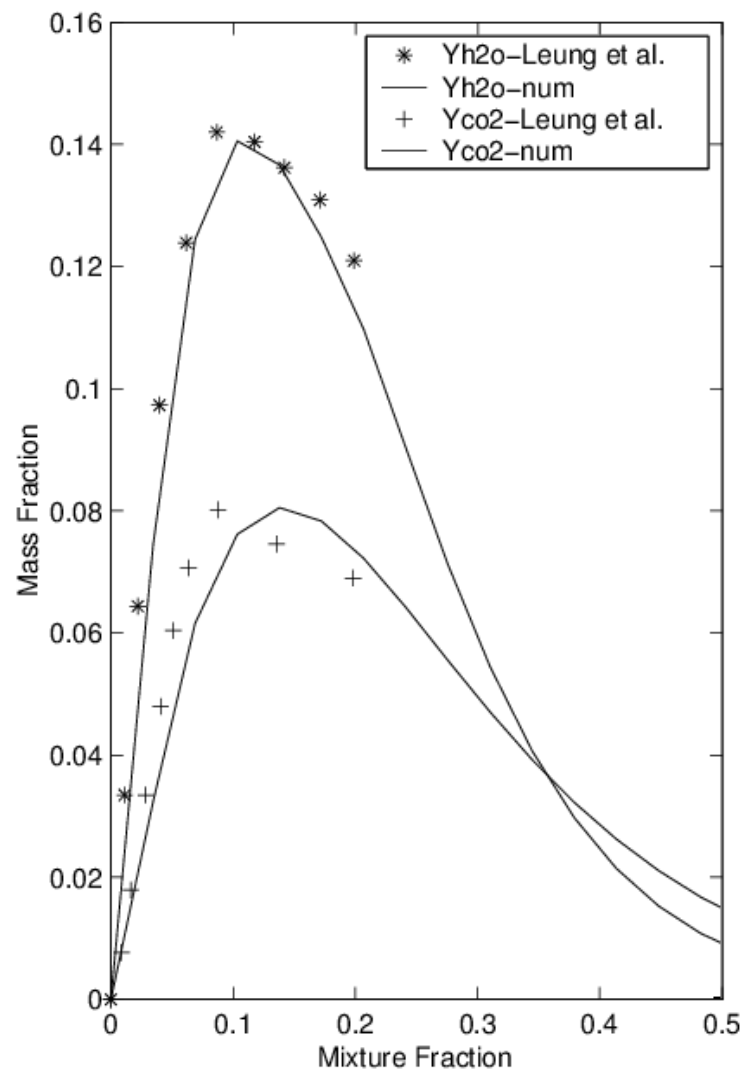

Figure 5. Numerical results for the mass fraction of $\mathrm{H}_{2} \mathrm{O}$ and $\mathrm{CO}_{2}$ along the mixture fraction space.

\section{CONCLUSIONS}

In this work we have developed a method to obtain a reduced kinetic mechanism for propane diffusion flames, considering steady-state and partial equilibrium assumptions. Good agreement has been obtained between predictions and measurements for the major species $\mathrm{H}_{2} \mathrm{O}$ and $\mathrm{CO}_{2}$. The main advantage of the strategy is the decrease of the work needed to solve the resultant system of chemical equations. Such reduction is proportional to the number of reactions of the complete mechanism, i. e., a decrease of one order of magnitude compared to the skeletal mechanism of 87-step for methane (Leung et al., 1993).

\section{ACKNOWLEDGEMENTS}

This research is being developed at the Federal University of Rio Grande do Sul - UFRGS. Andreis and Gomes thank the financial support from the Coordenação de Aperfeiçoamento de Pessoal de Nível Superior - CAPES - Brazil, and Prof. De Bortoli gratefully acknowledges the financial support from the Conselho Nacional de Desenvolvimento Científico e Tecnológico - CNPq - Brazil, under process 303007/2009-5. 


\section{REFERENCES}

Anetor, L., Osakue, E., and Odetunde, C., 2012, Reduced Mechanism Approach of Modeling Premixed Propane-Air Mixture Using ANSYS Fluent, Engineering Journal, Vol. 16, No. 1, pp. 6786.

Brenan, K. E., Campbell, S. L., and Petzold, L. R., 1996, Numerical Solution of Initial-Value Problems in Differential-Algebraic Equations, 2nd Edition, Society for Industrial and Applied Mathematics.

Curran, H. J., Jayaweera, T. M., Pitz, W. J., and Westbrook, C. K., 2004, A Detailed Modeling Study of Propane Oxidation, in: Western States Section of the Combustion Institute, pp. 1-6.

Dongarra, J. J., Bunch, J. R., Moler, C. B., and Stewart, G. W., 1979, LINPACK Users Guide, Philadelphia: Society for Industrial and Applied Mathematics.

Kennel, C., Mauss, F., and Peters, N., 1993, Reduced Kinetic Mechanisms for Premixed PropaneAir Flames, In: Peters, N., Rogg, B. (Ed) Reduced Kinetic Mechanisms for Applications in Combustion Systems, Berlin: Springer, pp. 123-141.

Leung, K. M., and Lindstedt, R. P., 1995, Detailed Kinetic Modeling of C1-C3 Alkane Diffusion Flames, Combustion and Flame, Vol. 102, pp. 129-160.

Leung, K. M., Lindstedt, R. P., and Jones, W. P., 1993, Reduced Kinetic Mechanisms for Propane Diffusion Flames, In: Peters, N., Rogg, B. (Ed) Reduced Kinetic Mechanisms for Applications in Combustion Systems, Berlin: Springer, pp. 259-283.

Marazioti, P. E., and Koutmos, P., 2002, A Reduced Multi-Step Chemistry Scheme for the Oxidation of Propane Suitable for use into Complex Reactive Flow Calculations, in: Flow 2002, Patras, Greece, pp. 246-253.

Mehl, M., Curran, H. J., Pitz, W. J., and Westbrook, C. K., 2009, Chemical Kinetic Modeling of Component Mixtures Relevant to Gasoline, in: 4th European Combustion Meeting, Vienna, Austria, pp. 1-6.

Peters, N., 1988, Systematic Reduction of Flame Kinetics: Principles and Details. In: Kuhl, A.L. et al. (Ed) Dynamics of Reactive Systems. Part I: Flames, Progress in Astronautics and Aeronautics, American Institute of Astronautics and Aeronautics, Monmouth Junction, pp. 67-86.

Petrova, M. V., and Williams, F. A., 2006, A Small Detailed Chemical-Kinetic Mechanism for Hydrocarbon Combustion, Combustion and Flame, Vol. 144, pp. 526-544.

Petzold, L. R., 1982, A Description of DASSL: A Differential/Algebraic System Solver, Livermore: Sandia National Laboratories.

Qin, Z, Lissianski, V. V., Yang, H., Gardiner, W.C., Davis, S.G., and Wang, H., 2000, Combustion Chemistry of Propane: A Case Study of Detailed
Reaction Mechanism Optimization, Proceedings of the Combustion Institute, Vol. 28, pp. 1663-1669.

Steiner, H., and Bushe, W. K., 1998, LES of Nonpremixed Turbulent Reacting Flows with Conditional Source Term Estimation, in: CTR Annual Research Briefs, pp. 23-34.

Turns, S. R., 2000, An Introduction to Combustion: Concepts and Applications, 2nd Edition, Singapure: McGraw-Hill.

Received: September 30, 2012

Revised: October 30, 2012

Accepted: November 30, 2012 